\title{
Commentary: The ERS/ESTS clinical guidelines for evaluating fitness for radical treatment for lung cancer
}

The European Respiratory Society (ERS) and the European Society of Thoracic Surgeons (ESTS) have recently established a joint task force, composed of leading multidisciplinary experts on the functional evaluation of lung cancer patients, with the purpose of developing clinical evidencebased guidelines on the evaluation of fitness for radical therapy in patients with lung cancer. The results of this joint endeavor have been published in the European Respiratory Journal [1, 2].

Approximately $20-25 \%$ of lung cancer patients are operable; however, lung resection remains the only curative treatment for lung cancer, despite advances in alternative treatments. Recent advances in operative and perioperative management and the reassessment of lung function tests and exercise test modalities justify the re-evaluation of the ideal surgical candidates. Nonsurgical patients are usually treated with chemo- or radiotherapy, which have specific toxicities that need to be taken into account. The task force aims to review acute and long-term risks related to chemoand radiotherapy and make recommendations on alternative nonsurgical treatments. The conclusions of the guidelines will be summarised in this commentary to supplement the interesting and informative review by D. SuBotic in this edition of Breathe.

\section{Cardiologic evaluation}

All available information on the pre-operative cardiac risk was integrated into a functional algorithm for evaluation of the lung resection candidate. This algorithm was generated based on the best available scientific evidence and consensus opinion of experts and recommends that cardiac evaluation should be the first step to assess a patients risk for surgery (figure 1) emphasising the importance of preliminary cardiologic assessment.

\section{Lung function tests}

The next step for patients with a low cardiological risk or with optimised cardiological treatment is to proceed with pulmonary evaluation (figure 2). The panel of experts agreed that predicted postoperative (ppo) forced expiratory volume in $1 \mathrm{~s}(\mathrm{FEV} 1)$ is not a reliable predictor of lung resection complications and should not be used alone to select lung cancer patients for surgery. However, it is a useful tool in combination with other diagnostics.

Diffusing capacity of the lung for carbon monoxide $(D L, C O)$ has been found to be an independent pre-operative predictor for the mortality and morbidity of lung resection [3-4]. The guidelines suggest that $D \mathrm{~L}, \mathrm{CO}$ should be routinely measured in lung resection candidates regardless of the results of spirometry. A cut-off ppo $D$ L,CO value of $30 \%$ predicted has been recommended as a high-risk threshold.

Perfusion scintigraphy is the most widely used method of predicting post-operative lung function in lung cancer patients prior to pneumonectomy [5]. However, it has been reported that lung segment counting can predict $\mathrm{ppoFEV} 1$ as accurately as perfusion scintigraphy $[6,7]$. Therefore, it has been recommended that lung segment counting should be used to calculate residual lung function and only in patients with borderline function perfusion scintigraphy should be used.

\section{Exercise tests}

Exercise tests are commonly used to evaluate the whole cardiopulmonary and systemic oxygen delivery systems under stress in order to estimate the physiological reserve of the patient after surgery. It is predicted that if a patient cannot perform well on an exercise

\section{A. Brunelli \\ Division of Thoracic Surgery Ospedali Riuniti \\ Ancona \\ Italy \\ brunellialex@gmail.com}

\section{Provenance}

Commissioned article, peer reviewed.

Competing interests None declared. 


\section{Figure 1}

Algorithm for cardiac assessment before lung resection in lung cancer patients. RCRI: Revised cardiac Risk Index; ECG: electrocardiogram; AHA: American Heart Association; ACC: American College of Cardiology; CABG: coronary artery bypass graft; PCI: primary coronary intervention; TIA: transient ischaemic attack. Taken from [1].

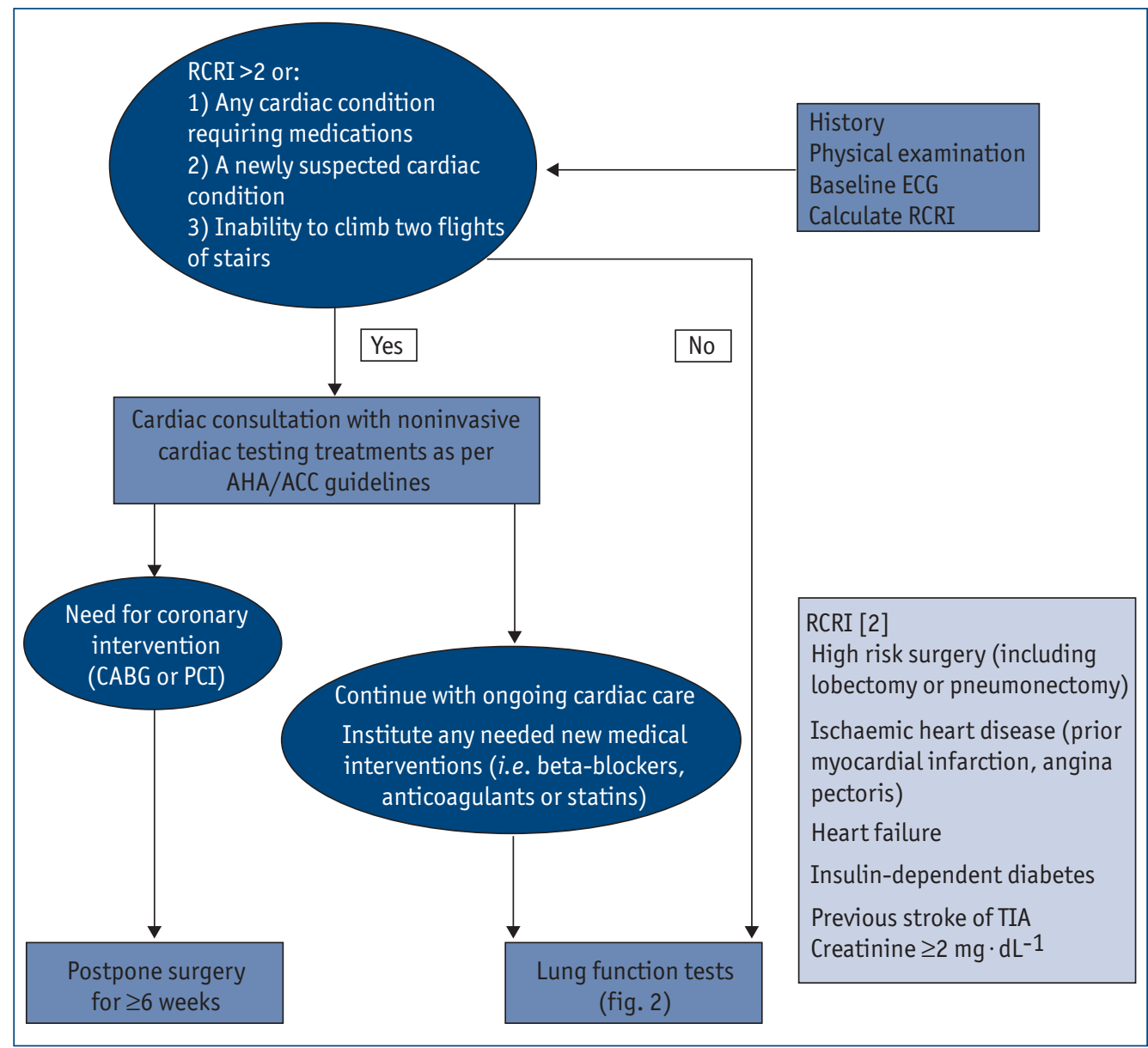

test that they will be unlikely to be able to withstand the stresses of surgery. However, a metaanalysis reported that exercise capacity was actually lower in patients who developed postoperative complications after lung resection [8]. Other studies have found a correlation between exercise capacity and mortality following lung resection and it is suggested that exercise tests should be carried out on patients with FEV 1 and $D \mathrm{~L}, \mathrm{CO}<80 \%$ pred.

\section{Low technology exercise tests}

Stair, 6-min walk distance and shuttle tests are the most widely used low technology exercise tests. The shuttle walk test has not been found to discriminate between patients with or without complications after surgery or to be reliable in estimating exercise capacity at a lower range. It is only advised for screening and not as a stand alone test. In contrast, stair climbing has been found to be superior at predicting the likelihood of morbidity and mortality after lung resection compared with spirometry measurements. Stair climbing is a costeffective method for firstline screening to immediately select patients who are safe to undergo surgery and those who need further more sophisticated tests. The 6-min walk test has not been found to be reliable in distinguishing patients fit for surgery and therefore should not be used in pre-operative decisions.

\section{Cardiopulmonary exercise testing}

Cardiopulmonary exercise testing is usually performed on a bicycle or treadmill in a controlled environment allowing for good reproducibility sumption $\left(\mathrm{VO}_{2}\right.$, peak $)$ is used to measure exercise capacity. Currently there is a consensus that $V_{\mathrm{O}_{2} \text {, peak }}>20 \mathrm{~mL}$ per $\mathrm{kg}$ or $>75 \%$ pred qualifies patients for resection and $V_{\mathrm{O}_{2} \text {, peak }}<10 \mathrm{~mL}$ per $\mathrm{kg}$ or $<35 \%$ pred indicates a high risk for any resection and these should be used as cut-off values. $V_{O_{2}}$ peak measurements should be considered as the most important factor for exercise capacity for predicting postoperative complications.

\section{Future trends in pre-operative workup}

The inclusion of daily physical exercise in the preoperative work-up could be used as an additional and standardised results. Maximal oxygen con- 
test to compliment more sophisticated measurements. Exercise $D \mathrm{~L}, \mathrm{CO}$ could also be an interesting parameter to measure since impairment of $D \mathrm{~L}, \mathrm{CO}$ reflects poor recruitment of pulmonary capillary and alveolar volume.

\section{Patient care management Rehabilitation before and after surgery}

Currently, evidence is insufficient to clearly recommend pulmonary rehabilitation in surgical lung cancer patients. However, pulmonary rehabilitation in COPD patients has been found to improve $\mathrm{VO}_{2}$ rate before surgery which decreased the number of late complications after surgery [9]. In addition, pre-operative training programmes have led to a reduction in the length of hospital stays and complications in COPD patients with lung cancer [10]. Smoking cessation before surgery has a positive impact on the rate of complications after surgery [11] and it is therefore recommended to cease smoking 2-4 weeks prior to surgery.

\section{Scoring systems}

Scoring systems designed specifically for lung resection including the cardiopulmonary risk index, the predictive respiratory quotient and the EVAD system (age, FEV 1 and $D L, C O$ ) have all been unreliable at predicting the risk of morbidity and mortality for individuals [12-15]. Therefore, it is not recommended that scoring systems should be used as standard care; however, they may be a useful tool when assessing a group of patients for surgery.

\section{Thoracotomies and the intensive care unit}

The guidelines state that systematic admission to the intensive care unit (ICU) after thoracotomy should not be implemented and when a highdependency unit (HDU) is available no patients should be admitted to the ICU. Only in an emergency situation such as organ failure, patients should be admitted to the ICU. Patients with a high risk of complication, those who have undergone complex pulmonary resection and those with a marginal cardiopulmonary reserve should be admitted to the HDU after surgery. Low risk patients should be sent to a specialised thoracic surgical unit after surgery.

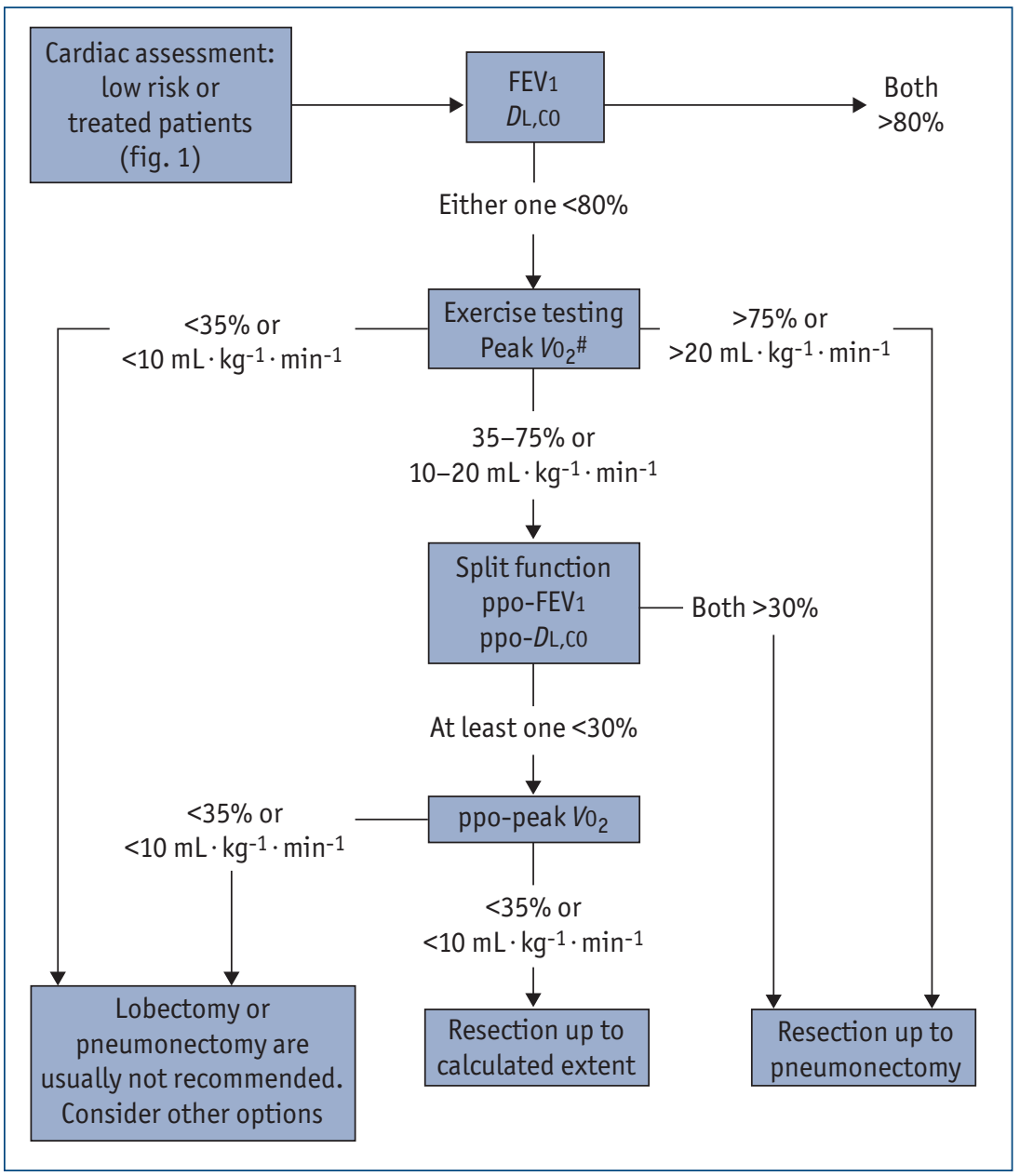

Figure 2

Algorithm for assessment of cardiopulmonary reserve before lung resection in lung cancer patients. \#: If peak $\mathrm{V}_{2}$ is not available, cardiopulmonary exercise testing can be replaced by stair climbing; however, if altitude reaching during stair climbing is, $<22 \mathrm{~m}$, cardiopulmonary exercise testing with peak $\mathrm{VO}_{2}$ measurement is highly recommended. Taken from [1].

\section{Surgical techniques Combined cancer and lung vol- ume reduction surgery}

Lung volume resection surgery (LVRS) produced significant improvements in exercise capacity and survival in patients with upper lobe emphysema $[16,17]$. Better health status and lung function has been noted after LVRS compared with normal medical treatment and rehabilitation $[18,19]$. Long-term survival after LVRS has also been improved compared with other modalities of treatment. In selected high-risk patients with hyperinflated lung and a poorly perfused tumourcontaining lobe anatomical lobectomy combined with LVRS has produced beneficial effects in terms of survival. Based on this evidence it was 
recommended that anatomical lobectomy with or without LVRS should be performed in well selected COPD patients with lung cancer.

\section{Compromised parenchymal spar- ing resections and minimally invasive techniques}

Parenchymal sparing resection or sublobar resections include segmentectomy and wedge resection. Patients recommended for segmentectomy are as follows:

a) Stage IA with margins of resection $>1 \mathrm{~cm}$.

b) Stage I patients with poor lung function.

c) Lung resection after prior lobectomy.

Wedge resections are recommended in the following circumstances:

a) Stage IA (tumours $<2 \mathrm{~cm}$ )

b) Small peripheral adenocarcinoma with air-containing image on high-resolution computed tomography scans.

\section{Chemo- and radiotherapy}

\section{Neoadjuvant chemotherapy}

The advantages of neoadjuvant treatments for resectable and operative lung cancer are currently being examined in future studies. To date, several studies have reported advantages for morbidity and mortality following induction therapy after pneumonectomy [20-22]. However, in recent trials induction chemotherapy in pneumonectomy has led to high levels of mortality and morbidity especially in right sided pneumonectomy [23, 24]. More studies are required to make a judgement on the use of induction chemo- and radiotherapy. It is recommended that after induction chemo- or radiotherapy, new functional evaluation should be carried out prior to surgery.

\section{Definitive radio- and chemo- therapy}

The greatest limitation to definitive radiotherapy is radiotherapy-induced lung toxicity which is het erogenic across studies due to different scoring systems. The risk of developing radiation pneumonitis-induced lung toxicity can be estimated by calculating the dose-volume histogram of the lung, including V20 and mean lung dose [25, 26]. Therefore this calculation should be carried out prior to treatment to determine the risk of toxicity. There is too little evidence on the safety of definitive chemotherapy to make a formal recommendation on its use.

\section{Alternatives to surgery}

For medically inoperable nonsmall cell lung cancer (NSCLC) the best established method for treatment is radiation alone which appears to increase survival rates. Continuous, hyperfractionated, accelerated radiotherapy (CHART) is the preferred method compared with conventional radiotherapy because it has been shown to provide improved local control and survival. In stage I NSCLC patients at high surgical risk, stereotactic radiotherapy should be considered as a good alternative to surgery.

\section{Who should treat thoracic patients and where should they be treated?}

Ideally a multidisciplinary team made up of a thoracic surgeon specialising in lung cancer, a medical oncologist, a radiation oncologist and a pulmonologist should manage lung cancer patients. Lung cancer patients undergoing surgery should be admitted to specialised centres with qualified thoracic surgeons, since specialisation has been shown to improve resectability, postoperative mortality and long-term survival. Surgery should also be carried out in centres with an adequate volume of cases (minimum surgical volume of 20-25 major lung resections per year) as this has a positive impact on resectability, postoperative mortality and long-term survival. In addition, there is also a positive impact of volume on the results of chemotherapy and radiotherapy. Radiotherapy should be performed by radiologists that routinely treat patients with this modality.

\section{Summary}

Despite advances in alternative treatments, lung resection remains the only curative treatment for lung cancer. Preliminary cardiologic assessment should be the first step to assess patients for surgery followed by pulmonary evaluation for those with low cardiological risk. DL,CO should be routinely measured in lung resection candidates as it has been seen to be an independent pre-operative predictor of mortality and morbidity. Stair climbing can be used for first-line screening to select patients for more sophisticated tests. $\mathrm{VO}_{2^{\prime}}$ peak is the most important factor for exercise capacity for predicting postoperative complications. There is 
no clear evidence for scoring systems or rehabilitation in selecting lung resection candidates. ICUs should be reserved for patients with major complications such as organ failure. Anatomical lobectomy with or without LVRS should be performed in well selected COPD patients with lung cancer. Additional studies are required to make adequate judgements on induction chemo- and radiotherapy and definitive chemotherapy. Stereotactic radiotherapy should be considered as a good alternative to surgery in stage I NSCLC patients at high surgical risk. Surgery and radiotherapy should be carried out by trained specialists who routinely treat patients with this modality.

\section{References}

1. Brunelli A, Charloux A, Bolliger CT. ERS/ESTS clinical guidelines on fitness for radical therapy in lung cancer patients (surgery and chemo-radiotherapy). Eur Respir J 2009; 34: 17-41.

2. Brunelli A, Charloux A, Bolliger CT, et al. The European Respiratory Society and European Society of Thoracic Surgeons clinical guidelines for evaluating fitness for radicial treatment (surgery and chemoradiotherapy) in patients with lung cancer. Eur J Cardiothorac Surg 2009; 36: 181-184.

3. Bousamra M 2nd, Presberg KW, Chammas JH, et al. Early and late morbidity in patients undergoing pulmonary resection with low diffusion capacity. Ann Thorac Surg 1996; 62: 968-974.

4. Ferguson MK, Reeder LB, Mick R. Optimizing selection of patients for major lung resection. J Thorac Cardiovasc Surg 1995; 109: 275-281.

5. BTS guidelines: guidelines on the selection of patients with lung cancer for surgery. Thorax 2001; 56: 89-108.

6. Zeiher BG, Gross TJ, Kern JA, et al. Predicting postoperative pulmonary function in patients undergoing lung resection. Chest 1995; 108: 68-72.

7. Win T, Laroche CM, Groves AM, et al. Use of quantitative lung scintigraphy to predict postoperative pulmonary function in lung cancer patients undergoing lobectomy. Ann Thorac Surg 2004; 78: 1215-1218.

8. Benzo R, Kelley GA, Recchi L, et al. Complications of lung resection and exercise capacity: a meta-analysis. Respir Med 2007; 101: 1790-1797.

9. Bobbio A, Chetta A, Ampollini L, et al. Preoperative pulmonary rehabilitation in patients undergoing lung resection for nonsmall cell lung cancer. Eur J Cardiothorac Surg 2008; 33: 95-98.

10. Sekine Y, Chiyo M, Iwata T, et al. Perioperative rehabilitation and physiotherapy for lung cancer patients with chronic obstructive pulmonary disease. Jpn J Thorac Cardiovasc Surg 2005; 53: 237-243.

11. Moller A, Villebro N. Interventions for preoperative smoking cessation. Cochrane Database Syst Rev 2005; 3: CD002294.

12. Pierce RJ, Copland JM, Sharpe K, et al. Preoperative risk evaluation for lung cancer resection: predicted postoperative product as a predictor of surgical mortality. Am J Respir Crit Care Med 1994; 150: 947-955.

13. Epstein SK, Faling LJ, Daly BD, et al. Predicting complications after pulmonary resection. Preoperative exercise testing versus a multifactorial cardiopulmonary risk index. Chest 1993; 104: 694-700.

14. Ferguson MK, Durkin AE. A comparison of three scoring systems for predicting complications after major lung resection. Eur J Cardiothorac Surg 2003; 23: 35-42.

15. Melendez JA, Barrera R. Predictive respiratory complication quotient predicts pulmonary complications in thoracic surgical patients. Ann Thorac Surg 1998; 66: 220-224.

16. Meyers BF, Yusen RD, Guthrie TJ, et al. Results of lung volume reduction surgery in patients meeting a national emphysema treatment trial high-risk criterion. J Thorac Cardiovasc Surg 2004; 127: 829-835.

17. Naunheim KS, Wood DE, Mohsenifar Z, et al. Long-term followup of patients receiving lung-volume-reduction surgery versus medical therapy for severe emphysema by the National Emphysema Treatment Trial Research Group. Ann Thorac Surg 2006; 82: 431-443.

18. Fishman A, Martinez F, Naunheim K, et al. A randomized trial comparing lung-volume-reduction surgery with medical therapy for severe emphysema. N Engl J Med 2003; 348: 2059-2073.

19. Tiong LU, Davies R, Gibson PG, et al. Lung volume reduction surgery for diffuse emphysema. Cochrane Database Syst Rev 2006; 4: CD001001.

20. Stamatis G. Risks of neoadjuvant chemotherapy and radiation therapy. Thorac Surg Clin 2008; 18: 71-80.

21. Roberts JR, Eustis C, Devore R, et al. Induction chemotherapy increases perioperative complications in patients undergoing resection for non-small cell lung cancer. Ann Thorac Surg 2001; 72: 885-888.

22. Depierre A, Milleron B, Moro-Sibilot D, et al. Preoperative chemotherapy followed by surgery compared with primary surgery in resectable stage I (except T1N0), II, and IIIa nonsmall- cell lung cancer. J Clin Oncol 2002; 20: 247-253.

23. Garrido P, Gonzalez-Larriba JL, Insa A, et al. Long-term survival associated with complete resection after induction chemotherapy in stage IIIA (N2) and IIIB (T4N0-1) non small-cell lung cancer patients: the Spanish Lung Cancer Group Trial 9901. J Clin Oncol 2007; 25: 4736-4742.

24. Gilligan D, Nicolson M, Smith I, et al. Preoperative chemotherapy in patients with resectable non-small cell lung cancer: results of the MRC LU22/NVALT 2/EORTC 08012 multicentre randomised trial and update of systematic review. Lancet 2007; 369: 1929-1937.

25. Graham PH, Gebski VJ, Langlands AO. Radical radiotherapy for early nonsmall cell lung cancer. Int J Radiat Oncol Biol Phys 1995; 31: 261-266.

26. Kwa SL, Lebesque JV, Theuws JC, et al. Radiation pneumonitis as a function of mean lung dose: an analysis of pooled data of 540 patients. Int J Radiat Oncol Biol Phys 1998; 42: 1-9. 